\title{
Research on the Education Mode of Practical Communication Talents Cultivation Based on the Characteristics of Agricultural Universities Rural Culture Service
}

\author{
Bin $\mathrm{LI}^{1, a}$, Su HUO ${ }^{2, b}$,Meng-Xia ZHANG ${ }^{3, \mathrm{c}}$ \\ 1 Jilin Agricultural University, No.2888.Xincheng Street, Changchun, China, 130118 \\ 2Jilin University, No. 2699.Qianjin Street, Changchun, China, 130013 \\ ${ }^{3}$ Jilin Agricultural University, No.2888.Xincheng Street, Changchun, China, 130118 \\ a105289129@qq.com, b280339877@qq.com, c105289129@qq.com
}

Key words: Agricultural Universities; Communication Education; Characteristic; Rural Culture

\begin{abstract}
Communication education is developing at high speed in China, but there is a vague situation in the orientation and development direction of communication undergraduate education. To the present communication education, it's crucial to understand the nature of communication education correctly, analyze the advantages and disadvantages of universities and explore the way of characteristic development in universities. This paper analyzes the situation of communication education in agricultural universities and tries to explore the education mode of communication from the aspects of curriculum design, subject development, vocational planning and so on.
\end{abstract}

\section{Introduction}

With the development of information science and biology science, China's agriculture is gradually moving from the traditional meaning to the direction of modernization. New comprehensive and rapidly developing agriculture has become an important force of economic development. Increase the intensity of the spread of science and technology, using the advantages of modern media to transform scientific and technological achievements into productive forces quickly. It needs to cultivate the interdisciplinary talents of both media knowledge skills and agricultural scientific knowledge urgently, then the agricultural university education will adapt to the new situation needs.

Faced with the current situation of more than 800 media - related undergraduate courses in the country, agricultural universities only break through the traditional way of thinking, and seek education survival opportunities in the agricultural dissemination and the mass media, they will have the characteristics of development.

The concept of "communication education" was born in the 1980s in the United States, from the university of Carolina department of journalism, Richard Cole, "the United States news, mass communication education status of the paper." China's Ministry of education approved the pilot communication undergraduate program from 2001 to April 2016, there are 74 colleges have established the communication undergraduate major in five years. From the concept of communication education implanted to more than 20 colleges and universities to set up communication science, communication science settled in the history of China's institutions of higher learning is still characterized by exploratory practice, the idea of running schools and personnel training objectives is also to explore the perfect in the process. It should be said that communication is a discipline, which is based on the integration of many subjects at the crossroad. Even in the United States where it originated, there is no such thing as "communication".

\section{Optimize the Curriculum and Highlight the Characteristics}

\section{Communication Curriculum Arrangement Analysis}

From the institutions of colleague to open the major of communication, about one fourth of communication courses and training orientation is not very clear. According to the faculty of 
humanities and social science, many universities have adapted to the relative liberal arts, which is based on existing journalism or radio and television related majors. More often, the institutions that experience is not very rich is not according with the characteristics of professional disciplines and employment market demand for curriculum to setting course. There are a lot of situations relied on teaching on teachers' own or taking classes in other schools.

Under the condition that teachers and equipment are not very sufficient, the communication is located in an embarrassing situation. Crown with memory of communication on the surface, but privately it offers a variety of courses to students on the content. On the one hand, the college takes into account the practical skills of students after graduation, so it vigorously provides radio, television, Internet and other media technology courses; On the other hand, it is deeply lacking in the theoretical cultivation of students' humanistic, artistic and journalistic aspects. On choice of professional student employment satisfaction can direct feedback out of the lack of school curriculum, media technology not confused, and even their media production parts are less than short-term students in a computer training program.

\section{Communication Curriculum Follows the Change of Media}

They define communication as the direction of radio, television, art, or media production, which is a manifestation of the lack of a thorough understanding of professional attributes. From the existing undergraduate curriculum of communication studies, many colleges tend to develop their own original ability of running a school. They have formed a curriculum system for their talent development program in curriculum matching of news series courses, communication theories, media theories, media skills and general courses. Setting in the dissemination of professional teaching institutions, many colleges have more than two kinds of curriculum arrangement of complementary perfect to understand the communication education, they also meet the needs of learning differences between different channels which the arts and sciences are accepted. For example, Communication University of China set the direction of network communication and media market investigation and analysis under the communication. Excepting public basic courses the former includes communication, press theory, history of Chinese and foreign journalism, public opinion, introduction to network communication, news gathering, news writing, news editing, news commentary, network communication technology, net news editing, web design, computer graphics, electronic commerce, online advertising, audio-visual language and so on.

It is supported by journalism, communication and statistics. The courses includes communication, media studies, basic writing, mathematics, basic statistics, marketing, media management, media market investigation and analysis, multivariate statistical analysis, sampling principle and method, questionnaire design, social investigation method, the audience ratings survey, investigation and analysis, research, advertising effect SPSS statistical software application, market research model technology and so on. For the strong ability of running a school and the Journalism education has a long history of well-known colleges and universities, make full use of teaching resources courses to achieve good teaching effect can be achieved, but for a lot of local colleges and universities and professional colleges is still very difficult, it is difficult to set up the course from the communication discipline meant.

In recent years, agricultural colleges and universities should not ignore the characteristic integration of curriculum setting in the educational practice of communication. In view of the fact that these institutions don't have enough experience and conditions for setting up relevant majors, we should take the two aspects of the entrance of students and the export of employment as the breakthrough point of educational orientation. Therefore, in addition to news courses, communication theories and media analysis courses and mass media technology courses, we should consider setting up regional culture and agricultural survey courses.

What is more important is to reflect the tendency of serving the place and agriculture in the course of teaching. Because of the teaching characteristics of the case and the evidence in communication, we can achieve the training goal in the teaching material use and the teaching method, this kind of practice can serve the local primary level media and gradually achieve the 
goal that the education positioning of the spread of agriculture through the curriculum establishment. The Agricultural communication series of teaching materials which is wrote by media teachers who come from Qingdao Agricultural University Institute is very characteristic from years of teaching experience and practice. The books take into account the communication professional attributes and agricultural college background. They can be used as reference.

\section{Deepening the Ability Relying on Advantageous Subjects}

\section{Depending on the Agricultural University Discipline}

Open media education in agricultural universities should be said that it has certain shortcomings in news communication education resources. From the formation of the teaching staff to all aspects of the discipline construction, they are in the process of perfection and development. For example, Beijing Jiaotong University's communication studies have their own distinctive features, their communication studies which backed by a certain strength of the Institute of humanities has a very good reputation in English teaching team. Therefore, when the school itself in the gap between the professional ability, it should be in their own advantages of teaching resources in the middle and lower, and find a living space for the local conditions of communication studies.

In agricultural universities almost weak conditions, the college should discover the advantages of good traditional agricultural education resources and link the role of senior experts in agricultural institutions in rural society, this point can not be ignored. Technology promotion and guidance of agricultural production are the most common form of service in agricultural university teachers and students, they exist more in interpersonal communication and mass media operation. They begin with an empirical discipline rooted in agricultural institutions and establishes partnerships with professionals in communication studies. Integrate the communication major of agricultural colleges with the outstanding subject resources of the University.

On the basis of communication studies, we will gradually improve the communication research experimental centers of various disciplines, then it will makes the professionals enter the research center selectively at school, and in this way, they can undertake agricultural science popularization activities and shoot and produce relevant scientific and educational contents. At the same time, it can broaden the channels of communication between the discipline and the agricultural extension, not only on a regular basis or waiting for the media to come home service, but actively become the guide of farmers' technical needs. It also provides more investigation and data analysis to the subject of teaching and research development, promote dominant disciplines in agricultural colleges teaching and scientific research capabilities steadily, this process is a good opportunity to deepen the dissemination of science education and ability to present teaching achievements.

\section{Given the Training in the Related Fields of Agricultural Practice}

The source of students decides the teaching mode, but also reflects the character of university culture. The agricultural college students mostly from rural areas, and is to work to the countryside in the traditional employment, this kind of "innate" campus environment is also conducive to the implementation of education. The rural environment is relatively backward, the degree of civilization of the people is not high, this is the media presented with ordinary city information dissemination different occupation moral requirements. Pro-agriculture should be the basis of emotional education orientation of agricultural colleges and universities, and it should be the realization of "prerequisite integration education for farmers' spread and talents.

In the process of students' learning and ability training, it always serves the purpose of serving the rural areas, this is not only beneficial to the teaching process, but also lays a professional ethical foundation for the employment direction of students. For example, the CCTV host Dongpo Xiao, he positioned the program in interviews with people with "local feelings, wonderful life". He used a simple and honest appearance, humorous, amiable hosting style, enlighten and educate the farmer's spiritual world with laughing. Media practitioners "to agriculture" dissemination still stay in a strong "preconceived" subjective position, and they are not very understanding of the various 
information needs about rural audience and new countryside construction. It leads to what we see in the agricultural situation unsatisfactory conditions. In the reflection of "new countryside "construction of the report, the presentation with many outstanding typical material life level is high, and it does not consider the attitudes of farmers.

Reporter, director and other media practitioners, in line with the understanding of the countryside during school learning, still put farmers in the position of vulnerable information reception, and rigidly put the subjective evaluation of media symbols into the media. This situation has caused farmers to be disgusted with the use of the media and biased towards new rural construction. Many agricultural colleges and agricultural disciplines and strong agricultural academic atmosphere is the media education resources which a professional agricultural college students should not ignore. Utilization of agricultural curriculum and service of agricultural communication channels can achieve the double effect of talent cultivation.

\section{Taking Career Planning as Education Direction on the Base of Practical Rural Culture Service}

\section{Establish Communication Students Career Plan}

China's higher education law requires students to the creative spirit and practical ability training in higher education. Especially the modern media industry is based on high-tech conditions, the operation skills are the basis of the core element is to cultivate creative consciousness and creative ability of students. With increasing employment pressure, higher education ability of occupation education year by year as a measure of social demand, more higher education experts to set up the occupation career of university curriculum calls for more unilateral consideration can be verified as one falls, another rises, students for four years during the period of school education training mode has been unable to match with social development needs of the industry. For the dissemination of students need to face the job The future industry is rapidly changing, the mass media industry's rapid development affects the related industry changes, so far, the media industry has become China's GNP by more than $20 \%$.

Therefore, training media professionals should be from the start of the students for their future occupation planning, prospectively determined the growth point of discipline and education. Communication is western learning into China, while abroad is not a discipline, but the research in empirical characteristics and practical ability is gained in social science, the formation of information science nutrition. The characteristics of communication education in Colleges and universities should follow the laws of science, in practice for we should co-ordinate education and teaching so as to train qualified personnel to meet the needs of employment.

The employment situation in recent years the students from the school of communication, there are all kinds of companies to spread propaganda departments, such as marketing, advertising and public relations department; there are all kinds of mass media; and government propaganda and cultural departments. Students from the industry to have a preliminary understanding of trends talent communication education overall, but stay in the pursuit of the mainstream media, big city work environment become professional employment pressure, agricultural universities communication professional orientation can be another way.

\section{Build the Practical Culture Service Bridge for Student}

In practice, many aspects of leading teaching orientation involves communication education, it carries on the discussion from the perspective of teachers and students. Firstly, put forward the new requirements for teachers, teachers are required to reflect the degree of identity fusion, and the media or the media, characteristics of senior teachers. In many media professional teachers in the United States, there are experience in the media, and can be the most dynamic new media resources and media communication changes with the students. Teachers should keep up with recent changes in the industry, updating teaching content, improve students' news writing and new varieties of new media communication skills. For example, television and other media news, writing, editing, 
streaming media, the new development of digital technology, media convergence trend can be through the guidance of teachers for students to grasp.

Teaching methods should reflect the professional characteristics, change the old teaching mode, interactive mode of open teaching with media devices in a variety of activities and competitions to promote professional learning. Try some new teaching methods, such as case teaching method, simulation teaching method, cultural communication method of the interview, the school should also be innovative behavior timely for teaching evaluation standard of new teachers encourage communication. Secondly, billboards, newspapers, radio stations, large-scale activities, campus forum, campus web, video communication, event broadcast platform, strengthen students practice training.

The initiative to undertake the spread of information content of agricultural specialty in agricultural universities communication, in practice we choose the "the three rural service" theme to simulate the media practice, not only exercise the students' professional qualities, but also occupation moral emotion of students basic service and rural construction of a subtle influence.

\section{Conclusion}

The training courses, social practice, professional practice, graduation design and practice of comprehensive innovation practice become indispensable part of students' practice, different fixed practice the time, training requirements, development direction, the practice training stage to serve the needs of personnel training. Students can also through professional teachers agreed to take a variety of forms to participate in the competition.

\section{Acknowledgement}

This research was financially supported by Jilin province social science fund project: The new media of Jilin rural cultural communication mechanism in the perspective of empowerment (2016B270) and Jilin province education science planning office program: Research on education training mode of communication practical cultivation of talents based on rural culture service(GH170263).

\section{References}

[1] YangJi. Communication, Culture and Society: the British Public Communication Theory Perspective, Shanghai: Fudan University press.2016.

[2] LuoGang, Liu Xiangyu. Cultural Studies Reader. Beijing: Chinese Social Science Press.2010.

[3] Wu Tingjun. Science and Technology Development and Communication Revolution. Wuhan: Huazhong University of Science and Technology Press, 2011. 